\title{
Justification optimal operating parameters of the conveyor, which is the mechanism of the header for two-phase harvesting by batch method, taking into account the minimization of losses of grain
}

\author{
Mikhail Konstantinov ${ }^{1, *}$, Ivan Gluchkov ${ }^{1}$, and Igor Ognev² \\ ${ }^{1}$ Federal state budgetary educational institution of higher education «Orenburg state agrarian \\ University», Orenburg, Russia \\ ${ }^{2}$ Federal State Autonomous Educational Institution of Higher Education «Ural Federal University \\ named after the first President of Russia B.N.Yeltsin»,Ekaterinburg, Russia
}

\begin{abstract}
The object of research is the conveyor, which is the mechanism of the header for two-phase harvesting by batch method. The aim of the research is to develop the design and technological process of the roll portion header, the most suitable for the conditions of arid climate with the justification of its main operating parameters. In the conditions of the steppe zone of the southern Urals, a separate method of harvesting grain crops is more preferable. The analysis of the structures windrowers allowed to develop a portion of the header. The technological process as a portion of the header includes two phases - mowing and subsequent accumulation of the grain mass on the conveyor, and then upload. The unloaded portions are joined with the stacked in the previous passage - this is how the roll strip is formed. This option of laying the roll can reduce the number of passes in the selection of about 4-5 times in comparison with the basic technology. This allows you to reduce the cost of selection and reduce the impact of heavy machinery on the soil. A special role in the work of the header plays a conveyor. It is established that the thickness of the layer of stems on the Reaper conveyor depends on the working length of the conveyor and the speed of movement of the unit on the field, the density and diameter of the stalk, the density of laying on the conveyor.
\end{abstract}

\section{Introduction}

The increase in grain production has been and remains one of the main tasks of the agricultural industry. There are two types of grain harvesting-direct harvesting (use of combine harvesters) and separate harvesting, which includes cutting the grain mass into rolls, its ripening and subsequent selection with threshing.

\footnotetext{
* Corresponding author: miconsta@yandex.ru
} 
In the conditions of the steppe zone of the southern Urals, often a separate method is more preferable. This process largely depends on the quality of the used roller reapers, which are classified according to several criteria: the principle of formation of the roll, the direction of unloading, the type of drive units, the type of aggregation with MES, etc.

However, the existing harvesters in the conditions of the dry-steppe zone at low yields do not provide a full load of threshing machines, form rolls of poor quality, and grain losses during the operation of these harvesters often exceed the permissible ones. Also, in accordance with the development Strategy of the Orenburg region until 2020 and for the period up to 2030, it is advisable to develop harvesting machines that reduce grain losses, reduce fuel consumption and soil compaction, increase productivity. Therefore, the issue of creating and using a header that meets the above requirements, which will improve the process of separate harvesting of grain crops, is relevant.

Based on the above, we can consider many ways to solve this problem. In particular, the purpose of our research was to develop the design and process of roll portion header, the most suitable for the difficult conditions of the South Ural climate with the justification of its main operating parameters. The object of research in this case was the belt conveyor of the header.

\section{Methodology}

Our analysis of existing designs of harvesters, functionally suitable for forming a portion of the roll allowed the development of the design portion of a roll of the Reaper. (Russian patent for invention № 2493685).

The main knots and mechanisms developed by harvesters include a frame platform, a cutterbar, a reel, a continuous conveyor, the device of drainage of sloping grain mass from the wheels of mobile energy means and the unloading device.

The technological process portions of the header, unlike traditional harvesters harvester roller base, involves two major phases - mowing and subsequent accumulation of the grain mass, and its subsequent unloading at some point. At the first stage, the stalks of grain crops are cut off by the cutting machine, stacked on a slowly moving conveyor with a reel, by moving the conveyor belt smoothly in the direction of the unloading device, gradually accumulating and forming a so-called roll portion. After the accumulation of the required amount of bread mass, the flap of the unloading device rises, and the speed of the conveyor increases significantly, as a result of which the bread mass is placed on the stubble. It should be noted that the portions discharged further are joined when unloading with already laid ones - this is how the roll strip made up of roll portions is formed. This option of laying the roll can reduce the number of passes in the selection of about 4-5 times in comparison with the basic technology. This method of harvesting significantly reduces the number of passes on the selection of the roll in comparison with its continuous unloading, which allows, in particular, to reduce the cost of fuel in the selection and reduce the impact of heavy machinery on the fertile soil layer. In more detail features of a design and technological process of a header are described in works $[1,2]$.

\section{Results and discussion}

A special role in the characteristic of the work of the header under consideration is played by the modes and parameters of the functioning of its conveyor, the design scheme of which is shown in Fig. 1. 


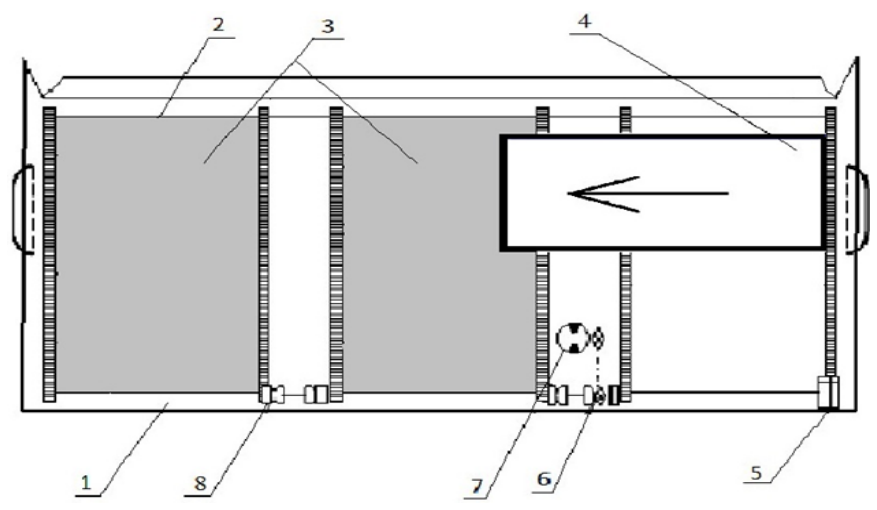

Fig. 1. Diagram of the conveyor portion of the harvester with the device of formation of stubble wings: 1-shaft; 2-output shaft; 3-belt; 4-chute; 5-tension mechanism; 6-chain transmission; 7-the hydraulic motor of the conveyor drive; 8-propeller shaft

The optimal design parameters of the conveyor and their justification were considered in a number of our works: 3, 4. In accordance with them, a number of the most significant indicators established earlier can be identified. Thus, the optimal values of the belt width from the edge of the header to the mass removal device from the wheels-2,21-2,24 $\mathrm{m}$, in the center-1,78 - 1,82 $\mathrm{m}$, the diameter of the drive shaft-0,068 - 0,074 $\mathrm{m}$, the diameter of the supports- $0,039-0,042 \mathrm{~m}$, the distance between adjacent supports- $0,358-0,366 \mathrm{~m}$, the number of support rollers-3 pieces [3, 4].

Speaking about the functional modes of the transporting device of the portion header, it should be borne in mind that the characteristics of the mowed culture have a significant impact on their optimal zones. For example, the height of the stand on the harvested field will affect the height of the cut and, therefore, the length of the cut part of the plant, which is crucial when laying the beveled mass on the conveyor. It is also worth noting the density of the stalk, which can affect the density of the beveled bread mass on the conveyor belt.

Removed plants cut cutting apparatus will be the portion of the stem of short length because of another characteristics of the standing crop of parusnosti (Fig. 2), which reduces the probability of their contact with the conveyor belt. We assume the length of these cut stems critical $\left(\ell_{\mathrm{kp}}\right)$ and determine its value.

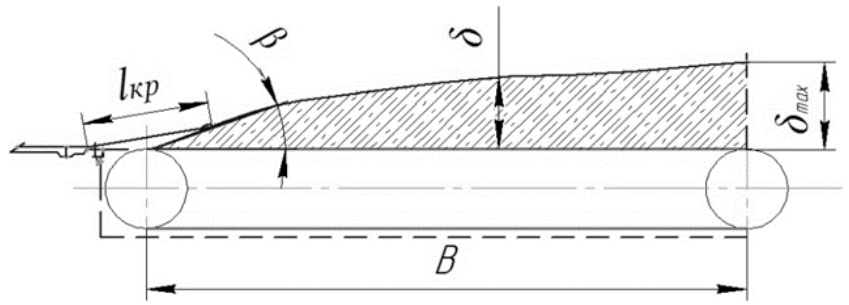

Fig. 2. Scheme of laying the stems on the conveyor

In most cases, the nature of the distribution of stems in height, density, grain yield is subject to the normal distribution law [5-7]:

$$
f(x)=\frac{1}{\sigma \sqrt{2 \pi}} \cdot e^{-\frac{1}{2}\left(\frac{x_{i}-\bar{x}}{\sigma}\right)}
$$

where $\bar{x}-$ is the average value; $\sigma-$ standard deviation 
The probability of hitting the height of the grain stand of the harvested field (normally distributed random variable) in the range from zero to $l_{k p}+h$, taking into account the ratio $\mathrm{H}_{\mathrm{cp}} / \sigma_{\mathrm{H}}>3$ for most stalks of cereal crops, is defined as [5]:

$$
P\left[0<H<\left(\ell_{K P}+h\right)\right]=\frac{1}{2}\left\{1-\Phi\left[\frac{\ell_{K P}+h-H_{c p}}{\sigma_{H}}\right]\right\}
$$

where $\Phi(H)$ - is the probability integral (Laplace function); $l_{\kappa p}-$ critical length of cut stem, $\mathrm{m} ; H_{c p},-$ average height of a stalk, $\mathrm{m} ; h$ - the height of the cut stems, $\mathrm{m}$.

Then the value of possible losses of the cut ear (losses of cut stems) CDK, expressed in $\%$, will be:

$$
Q_{c \kappa}=50\left\{1-\Phi\left[\frac{\ell_{K P}+h-H_{c p}}{\sigma_{H}}\right]\right\}
$$

From the expression (3) it is seen that the higher and the smoother the bread, the smaller the value of possible losses.

The approximate value of the critical length of the mowed stem can be determined using the following pattern:

$$
\ell_{K P}=\mu \cdot b
$$

where $\mu$-coefficient determined experimentally; $b-$ is the value of the passive zone between the cutting machine and the conveyor, $\mathrm{m}$.

The value of the coefficient $\mu$ is affected by the thickness of the beveled mass layer on the conveyor belt, which in turn depends on the operating speed of the unit, the length of the conveyor, the speed of the conveyor and other factors.

As can be seen from the expressions (4), crops in fields with a high degree of tiering can not be removed at a high cut, avoiding unnecessary and significant losses of grain. This is explained by the fact that the number of losses by the cut ear increases and the probability of cutting the ear by the cutting machine increases, which will lead to an increase in losses of free grain. There will also be a high degree of probability of loss and uncut ear.

For rationally oriented laying of the cut mass on the conveyor and prevent spreading of the stems in contact with the reel, it is necessary that the thickness of the layer on the conveyor does not exceed the maximum value, depending on the height of the cut and the average height of the stem:

$$
b_{\max }<\frac{2}{3}\left(H_{c p}-h\right)
$$

where $\delta_{\max }-$ the maximum thickness of the layer of stems on the conveyor header (in place of descent).

On the other hand, the value of $\delta_{\max }$ should be determined in terms of the possibility of laying short stems on the conveyor belt header.

As it is known [2, 5-7], the thickness of the formed layer of stems on the Reaper conveyor depends on the working length of the conveyor and the speed of the unit along the field, the speed of the conveyor, the density and diameter of the stalk, the density of laying on the conveyor and can be expressed approximately by: 


$$
\delta=c d^{2} K_{n} L \frac{V_{a z p}}{V_{T}}
$$

where $c$ - is the density of the stem, $1 / \mathrm{m} 2 ; d$ - stem diameter, $\mathrm{m} ; K_{n}$ - coefficient, taking into account the looseness of laying stems [74]; $L$ - conveyor length, $\mathrm{m} ; V_{\text {azp }}-$ speed of movement of the harvester through the field, $\mathrm{m} / \mathrm{s} ; V_{T}-$ speed of the header conveyor, $\mathrm{m} / \mathrm{s}$.

We Express the length of the conveyor belt from the expression (6):

$$
L=\frac{\delta V_{T}}{c d^{2} K_{n} V_{a z p}}
$$

In works $[1,7,8]$ considered some aspects of the formation of the header portion of the bread roll of the required quality. In the framework of these studies were analytically determined pattern, which determines the speeds of the conveyor in the accumulation period of the crop, taking into account, in particular, and the value of the length of the belt:

$$
V_{T}=\sqrt{2 f \cdot L \cdot g}
$$

where $f$-is the coefficient of friction of the stems on the conveyor belt; $g$ - acceleration of gravity $\left(9.81 \mathrm{~m} / \mathrm{S}^{2}\right)$.

It should be noted that this dependence does not take into account the possible loss of grain. Accordingly, it is advisable to compare this expression with the pattern (7):

$$
L=\frac{\delta V_{T}}{c d^{2} K_{n} V_{\text {arp }}}=\frac{V_{T}}{2 f g}
$$

From here we can Express the final form of the dependence determining the optimal intervals of the conveyor speed:

$$
V_{T}=\frac{2 \delta f g}{c d^{2} K_{n} V_{a z p}}
$$

Thus, the analytical dependence, allowing to determine the speed of the conveyor in the accumulation of mass, taking into account the permissible level of losses depending on the speed of the unit, the looseness of laying the mass, the thickness of the layer and the parameters of the stand on the harvested field.

The density of the stalk depends on a number of factors, for example, on the technology of sowing, seed germination, weather conditions (for the steppe zone of the southern Urals and Northern Kazakhstan, this value varies within 230-600 1/ $\mathrm{m}^{2}$. The coefficient of friction $\mathrm{f}$ of the stalks of grain crops ranges from 0.39 to 0.83 . The density of the stems at their location on the conveyor- $10-25 \mathrm{~kg} / \mathrm{m}^{3}$. The diameter of the wheel is within $0.008-0.012 \mathrm{~m}[6,7]$.

\section{Conclusions}

Based on the agrotechnical data and our calculations, it was found that the optimal speed of the conveyor belt during the accumulation of bread mass on the conveyor is $1.6-2.8 \mathrm{~m} / \mathrm{s}$.

The substantiation of the belt conveyor speed taking into account the minimization of losses made it possible to estimate the grain losses (\%) during the operation of the header 
under consideration. They were determined depending on the speed of the conveyor and the operating speed of the unit, as well as taking into account the ratio of the circumferential speed of the reel bar $(u)$ and the operating speed of the unit $\left(\mathrm{V}_{\text {arp }}\right): u=(1,2 \div 1,8) \mathrm{v}_{\text {arp }}$. The latter aspect allowed us to consider the impact of modes of operation of the reel on the grain losses behind the header portion. The resulting data were presented in the form of graphs of grain losses during the operation of the Reaper on the speed of movement of the reaping unit (Fig. 3) and the speed of the conveyor belt during the accumulation of portions of bread mass (Fig. 4).

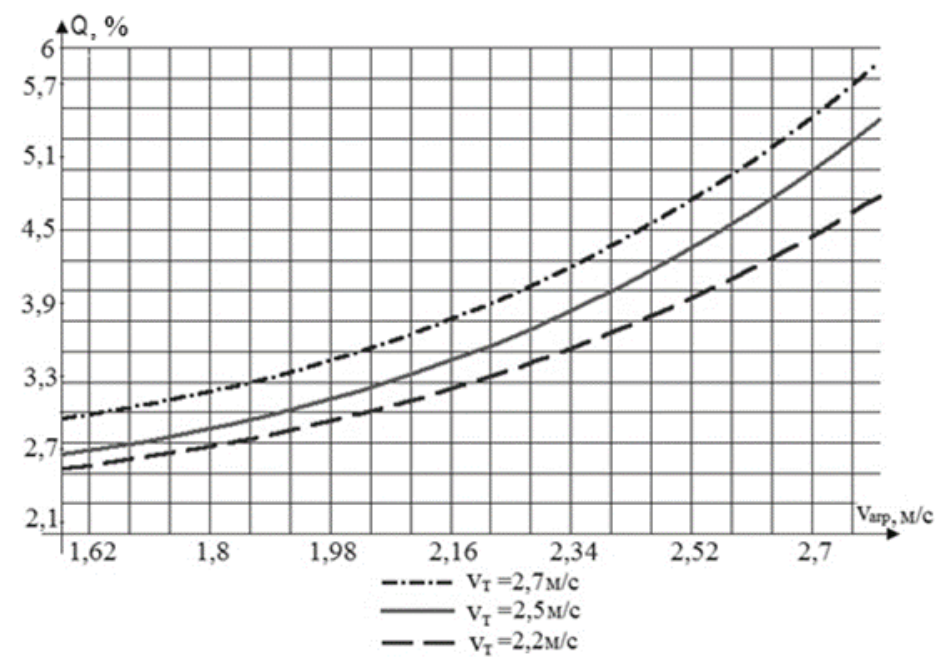

Fig. 3. Dependences of grain losses behind the Reaper on the speed of the reaping unit at different speeds of the conveyor belt

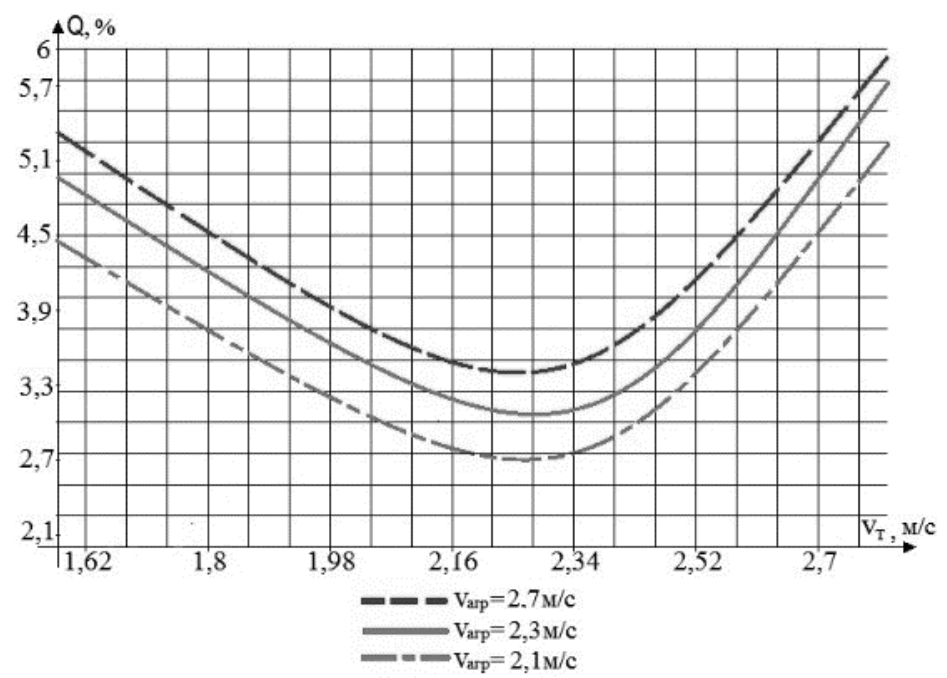

Fig. 4. Dependence of grain losses behind the header on the conveyor belt speed at different speeds of the unit

The obtained regularities show that in almost all the selected modes of operation of the header, grain losses are less than acceptable. In cases that represent an exception, it is possible to adjust the level of losses due to the selection of the conveyor speeds, the unit and the reel bar. 


\section{References}

1. M. M. Konstantinov, I. N. Glushkov, S. S. Pashinin, Scientific review, 11, 24-29, (2015)

2. M. M. Konstantinov, I. N. Glushkov, A. N. Kondrashov, Agricultural science agricultural production: a collection of reports of international scientific-practical conference dedicated to the 50th anniversary, 60-64, (2012)

3. I. N. Glushkov, I. V. Gerasimenko, News of Orenburg state agrarian University, 4 (66), 135-138, (2017)

4. M. M. Konstantinov, I. N. Glushkov, A. L. Osipov, Collection: the Current state of tradition and innovative technologies in the development of agriculture, part 2, Ufa, Bashkir GAU, 223-228, (2017)

5. A. S. Janburchin, Kolosovidnye machines and mechanisms, 152, (1977)

6. V. T. Selikhov, Cleaning and postharvest processing of grain. Kustanai: employee Tselinniks, 243-249, (1976)

7. I. N. Glushkov, S. S. Pashinin, M. M. Konstantinov, Design and organization of an effective process of harvesting crops. Edited by M. M. Konstantinov, 13-37, (2011)

8. M. M. Konstantinov, I. N. Glushkov, I. V. Gerasimenko, A. A., Panin, V. I. Kvashennikov, A. P. Lovchikov, News OGAU, 6 (62), 68-72, (2016) 